\title{
Chronic Tubal Ectopic Pregnancy with Diagnostic Conundrum: A Case Report
}

\author{
Vishal Sharma', Ravi Dutt Wadhwa \\ ${ }^{1}$ Assistant Professor, ${ }^{2}$ Professor \& Head, \\ Department of Obstetrics \& Gynaecology, SHKM Government Medical College, Nalhar, Haryana \\ Corresponding Author: Vishal Sharma
}

\begin{abstract}
Ectopic pregnancy is a life threatening condition and mostly ectopic pregnancies occurs in fallopian tube. The most common site of ectopic tubal pregnancy is ampulla. Ectopic pregnancy is a complication of pregnancy and usually easy to diagnose by ultrasonography during the first trimester of pregnancy. Due to limited healthcare resources in developing countries, women do not undergo for ultrasound examination during pregnancy which leads to late diagnosis. In most of cases women with ectopic pregnancy are asymptomatic, unless ruptured. The mean gestational age for clinical presentation of ectopic pregnancy is 7.2 weeks after the last normal menstrual period. In rural population, late presentations of ectopic pregnancies are more commonly seen because of lack of modern diagnostic ability. Present case report is a rare case of non-viable, unruptured, tubal ampullary chronic ectopic pregnancy of 12 weeks gestational age.
\end{abstract}

Keywords: Ectopic pregnancy, Unruptured, gestational age, ultrasonography

\section{INTRODUCTION}

Ectopic pregnancy is the result of implantation and subsequent development of embryo outside the endometrial cavity. Presentation ranges from acute hemoperitoneum to chronic ectopic. If ectopic pregnancy is not timely diagnosed and treatment, it can become a lifethreatening condition. ${ }^{[1]}$ Signs and symptoms of ectopic pregnancy include vaginal bleeding, abdominal pain, pelvic pain, a tender cervix, an adnexal mass, or adnexal tenderness [2]. In chronic ectopic there is formation of pelvic hematocele due to multiple small haemorrhages in the peritoneal cavity. Ectopic pregnancy occurs at a rate of $1 \%$ to $2 \%$ of pregnancies, though assisted reproductive technology has high rate of $4 \%$. Most common site of ectopic pregnancy is fallopian tube (93\% to $97 \%$ ). Of these, in turn, $13 \%$ are located in the isthmus, $75 \%$ are located in the ampulla, and $12 \%$ in the fimbriae ${ }^{[3]}$.

During the first trimester of pregnancy, $6 \%$ of maternal deaths are because of Ectopic pregnancy. Rarely an ectopic pregnancy progress asymptomatically into second trimester because it is unusual for the fallopian tube to dilate to a point of carrying second trimester fetus. This is an atypical case of chronic ectopic pregnancy with large adnexal mass without classical symptoms ${ }^{[4]}$

\section{CASE REPORT}

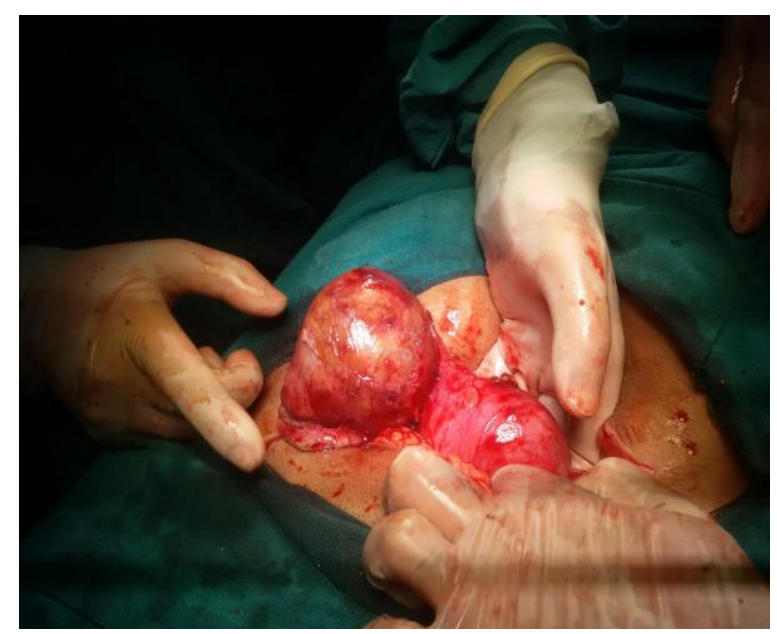

Fig 1: Right sided tubal lump of $6 \times 7 \mathrm{~cm}$ 


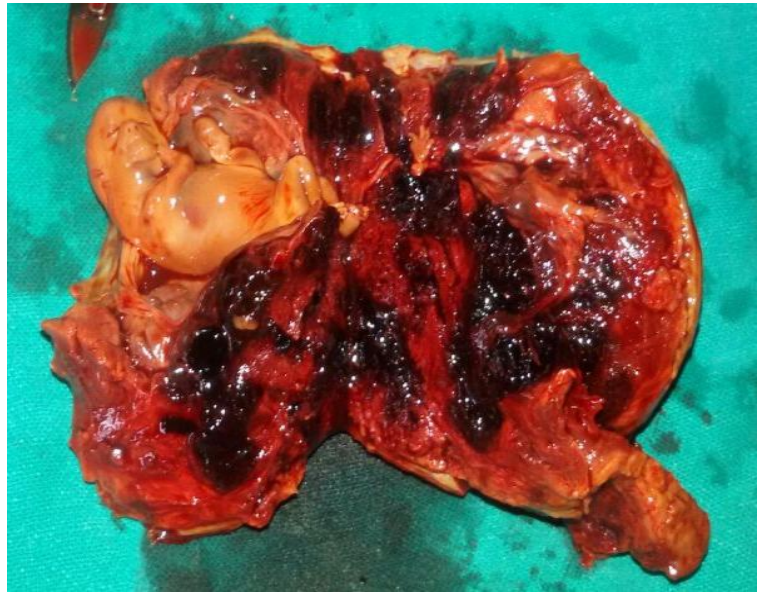

Fig 2: A dead macerated fetus of about 12 weeks gestational age with placenta

A 28 year old patient Gravida $3\left(\mathrm{G}_{3}\right)$ Para $2\left(\mathrm{P}_{2}\right)$ Live $2\left(\mathrm{~L}_{2}\right)$ presented to the OutPatient Department of Obstetrics \& Gynaecology, SHKM Government Medical College, Nalhar (Haryana) with history of pain abdomen on \& off since 15 days for which she took analgesics from some local practioner but the pain was not relieved. She experienced on and off blood spotting since 36 weeks. She was having regular menstrual cycles before that. She has not undergone any urine pregnancy test or ultrasound. She had previous 2 full term vaginal deliveries and had no risk factors for ectopic pregnancy. On examination, Blood Pressure was $120 / 80 \mathrm{~mm} \mathrm{hg}$, with mild to moderate pallor and pulse rate was 86 beats per minute. On abdominal examination there was mild suprapubic tenderness. On per speculum examination cervical os was closed with minimal spotting. Bimanual examination revealed normal sized uterus with no cervical motion tenderness with a lump of about 6 by $6 \mathrm{~cm}$, firm to hard in consistency palpable through right adenexa. Urine for human chorionic gonadotropin was negative. The diagnosis of ectopic pregnancy cannot be ruled out when urine pregnancy test is negative. Therefore we did quantitative measurement of serum beta-hcg levels, which was $14.4 \mathrm{IU} / \mathrm{ml}$ (reference range is $<1 \mathrm{IU} / \mathrm{ml})$. Serum level of cancer antigen 125 was measured, which was 32.3 $\mathrm{IU} / \mathrm{ml}$ (normal reference range is $0.1-35$ $\mathrm{IU} / \mathrm{ml}$ ), to rule out endometrioma and ovarian tumor. Transabdominal ultrasonography revealed a complex right adnexal mass $6 \times 6 \mathrm{~cm}$ with empty uterine cavity. The pouch of douglas was free from fluid. Patient's hemoglobin was $8 \mathrm{gm} / \mathrm{dl}$, blood group was A positive with normal liver and renal function tests. Exploratory laprotomy was done after obtaining informed written consent which revealed adhesions between the small gut loops hiding the right tube and ovary. These adhesions were released and a large right sided tubal lump of $6 \times 7 \mathrm{~cm}$ with firm consistency was exposed (Fig 1). Right sided salpingectomy with left sided tubal ligation was done after obtaining written consent for the same. A dead macerated fetus of about 12 weeks gestational age with placenta was obtained on cut section of the specimen, later it was sent for histopathology. (Fig 2)

\section{DISCUSSION}

Ectopic Pregnancy is the leading cause of first trimester pregnancy related morbidity and mortality mostly in developing countries. Most ectopic pregnancies (90\%) occur in the Fallopian tube which is commonly called as tubal pregnancies. The clinical presentation of chronic ectopic is similar to acute variant, although the symptoms are generally mild. One important feature to differentiate is the recurrent presence of a pelvic mass on bimanual examination in chronic ectopic. In addition there is more remote onset of pain, longer amenorrhoea and duration of symptoms in chronic ectopic. In chronic ectopic pregnancy the trophoblasts degenerate, production of beta-hcg ceases and pregnancy persists in the tube without rupture $^{[5] .}$ Inflammatory response occurs in peritoneal cavity because of the presence of blood, trophoblastic tissue, which results in adhesion formation. As there is high incidence of negative urinary pregnancy test thus it is often difficult to diagnose chronic ectopic preoperatively, reason being very less amount of live chorionic villi, subtle symptoms and poor specificity of ultrasound. The ultrasound findings may be 
similar to ovarian tumor, endometrioma, leiomyoma and pelvic inflammatory disease. The final diagnosis of an ectopic pregnancy is by histopathology of the specimen showing trophoblastic tissue. The most common location of tubal ectopic is ampullae of the fallopian tube ${ }^{[6] .}$ There are multiple risk factors for ectopic pregnancy including pelvic inflammatory disease, prior tubal surgery, tobacco smoking, history of infertility and the use of assisted reproductive technology. Ectopic pregnancy can be difficult to diagnose because symptoms often like those of a normal early pregnancy like breast tenderness, nausea, vomiting, frequent urination. Often, the warning signs of ectopic pregnancy are vaginal bleeding and pain

Early pregnancy transvaginal sonographic examination helps to identify the site of pregnancy and to diagnose ectopic pregnancy early. As chronic ectopic pregnancy can potentially cause rupture of the fallopian tube, mandating timely diagnosis. Late diagnosis of ectopic pregnancy leads to major complications in almost all cases and needs immediate surgical intervention. The treatment of advanced tubal pregnancy is always a total salpingectomy. ${ }^{[7]}$ It is difficult to perform conservative tubal surgery due to excessive deformation of fallopian tube, thus in our case total right sided salpingectomy was done. Future fertility is a serious concern in ectopic pregnancy. Early diagnosis of ectopic pregnancy in the unruptured state may facilitate conservative tubal surgeries like salpingostomy or medical treatment to achieve successful future pregnancy outcome ${ }^{[8] .}$ But conservative surgery is not possible in case of chronic ectopic because of distortion of normal tubal physiology.

\section{CONCLUSION}

Chronic ectopic pregnancy is a rare condition that can be life threatening. Clinical presentation is often misleading because of variability in symptomatology, depending on the patients' response to complex interaction between trophoblastic tissue and tubal bleeding. Accurate diagnosis is possible only after exploratory laparoscopy or laparotomy.

\section{Acknowledgement: None Conflict of Interest: None Source of Funding: None}

\section{Declaration of Patient Consent}

Appropriate patient consent was taken prior to publication in the journal.

\section{REFERENCES}

1. Murray H, Baakdah H, Bardell T, Tulandy T. Diagnosis and treatment of ectopic pregnancy, CMAJ. 2005; 173(8): 905-12.

2. Shao R. Understanding the mechanisms of human tubal ectopic pregnancy: new evidence from knockout mouse models, Hum Reprod. 2010; 259 (3):584-587.

3. Kirk E, Bourne T. Ectopic pregnancy. Obstet Gynecol Reprod Med. 2011; 21(7): 207-211.

4. Nkwabong ETincho EF. A case of a 26weeks ampullary pregnancy mimicking iud. Anatol J Obstet Gynecol. 2012; 1(2):1-3

5. Bouyyer J, Coste J, Fernandez H, Pouly JL, job spira N.sites of ectopic pregnancy; a ten year population based study of 1800 cases. Hum Reprod 2002;17(12):3224-30.

6. Tay JI Moore J, Walker JJ. Ectopic pregnancy.BMJ, 2000; 320 (7239):916-919.

7. Grimes DA. The morbidity and mortality of pregnancy: still risky business. J. Obstet Gynecol.1994; 170 (5):1489 -1494.

8. Radaelili T, Bulfamente G, Cetin I, Marconi, AM, Pardi G. Advanced tubal pregnancy associated with severe fetal growth restriction; a case report. The journal of Maternal and fetal and neonatal medicine. 2012; 13: 422-425.

How to cite this article: Sharma V, Wadhwa RD. Chronic tubal ectopic pregnancy with diagnostic conundrum: a case report. International Journal of Science \& Healthcare Research. 2021; 6(2): 192-194. DOI: https:// doi.org/10.52403/ijshr.20210435 